\title{
New oral anticoagulants in patients with nonvalvular atrial fibrillation: a review of pharmacokinetics, safety, efficacy, quality of life, and cost effectiveness
}

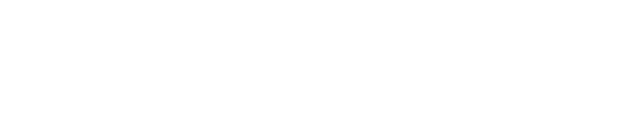

\author{
Helen Mani \\ Edelgard Lindhoff-Last \\ Johann Wolfgang Goethe-University \\ Hospital Frankfurt/Main, Department \\ of Internal Medicine, Division of \\ Haemostasis, Frankfurt, Germany
}

\begin{abstract}
Atrial fibrillation (AF) continues to be a leading cause of cerebrovascular morbidity and mortality resulting from cardioembolic stroke. Oral anticoagulation therapy has been shown to decrease the incidence of cardioembolic stroke in patients with AF by more than $50 \%$. Appropriate use of anticoagulation with vitamin $\mathrm{K}$ antagonists requires precise adherence and monitoring. A number of factors that potentially induce patients' dissatisfaction reduce quality of patient life. New direct oral anticoagulants, such as the direct factor Xa inhibitors rivaroxaban, apixaban, edoxaban, and the thrombin inhibitor dabigatran, were developed to overcome the limitations of the conventional anticoagulant drugs. However, models to optimize the benefit of therapy and to ensure that therapy can be safely continued are missing for the new oral anticoagulants. This review will briefly describe the new oral anticoagulants dabigatran, rivaroxaban, apixaban, and edoxaban with focus on their use for prevention of embolic events in AF. Moreover, it will discuss the safety, efficacy, cost data, and benefit for patients' quality of life and adherence.
\end{abstract}

Keywords: apixaban, edoxaban, rivaroxaban, dabigatran, oral anticoagulation

\section{Introduction to thrombosis prophylaxis with new oral anticoagulants (NOAC)}

Deep vein thrombosis, ischemic stroke, and pulmonary embolism are manifestations of the same disease process, summed up over 100 years ago by Rudolph Virchow. ${ }^{1}$ His hypothesis that thrombosis was the result of the interaction of the three factors - stasis of blood flow, hypercoagulability of the blood, and damage to the vascular endothelium - has become the basis of risk-association diagnosis in patients who have developed venous thrombosis embolism.

Atrial fibrillation (AF) is the most common tachyarrhythmia with prevalence of over $10 \%$ in older patients ( $>70$ years). AF is the leading cause of ischemic stroke, and stroke due to $\mathrm{AF}$ is one of the leading causes of death and adult disability. ${ }^{2}$ Besides rate and rhythm control, stroke prevention is the key management strategy for patients with nonvalvular atrial fibrillation and one or more additional risk factors for stroke. ${ }^{3}$

Thrombosis risk can be quantified using the $\mathrm{CHADS}_{2}$ or recently quantified $\mathrm{CHA}_{2} \mathrm{DS}_{2}$-VASc scores (documenting risk factors for stroke: history of congestive heart failure, hypertension history; age $\geq 75$ [or age $\geq 65$ years associated with one of the following: diabetes mellitus, coronary artery disease, or hypertension]; diabetes mellitus; stroke or transient ischemic attack or thromboembolism history; vascular
Correspondence: Helen Mani Johann Wolfgang Goethe-University Hospital Frankfurt/Main, Department of Internal Medicine, Division of Haemostasis, Theodor-Stern-Kai 7, 60590 Frankfurt, Germany Email Helen.Mani@kgu.de 
Table I Score systems evaluating thrombotic risk in patients with atrial fibrillation

\begin{tabular}{lll}
\hline Risk factor & $\begin{array}{l}\text { CHADS }_{2} \\
\text { score points }\end{array}$ & $\begin{array}{l}\text { CHA }_{2} \text { DS }_{2}-\text { VASC } \\
\text { score points }\end{array}$ \\
\hline $\begin{array}{l}\text { Congestive heart failure/left } \\
\text { ventricular dysfunction }\end{array}$ & $\mathrm{I}$ & $\mathrm{I}$ \\
Hypertension & $\mathrm{I}$ & $\mathrm{I}$ \\
Age $>75$ years & $\mathrm{I}$ & 2 \\
Diabetes mellitus & $\mathrm{I}$ & $\mathrm{I}$ \\
Stroke/transient ischemic & 2 & 2 \\
attack/thromboembolism & & $\mathrm{I}$ \\
Vascular disease & - & $\mathrm{I}$ \\
Age 65-74 years & - & $\mathrm{I}$ \\
Sex category (ie, female) & - & 9 \\
Maximum score & 6 & .
\end{tabular}

Notes: $\mathrm{CHADS}_{2}$ or $\mathrm{CHA}_{2} \mathrm{DS}_{2}-\mathrm{VASc}$ score, documenting risk factors for stroke: history of congestive heart failure, hypertension history; age $>75$ (or age $>65$ years associated with one of the following: diabetes mellitus, coronary artery disease, or hypertension); diabetes mellitus; stroke or transient ischemic attack or thromboembolism history; vascular disease history; sex category.

disease history; sex) (see also Table 1 ). ${ }^{4-6}$ By considering these additional risk factors the score is calculated to determine whether antithrombotic therapy is required or not. Current guidelines recommend oral anticoagulation with a score of 2 or more.

Anticoagulation with vitamin $\mathrm{K}$ antagonists (VKA), ever since their introduction in the 1950s, has been an enduring gold standard for stroke prevention in AF as well as for the prophylaxis and long-term treatment of venous thromboembolism. ${ }^{7,8}$ VKAs such as phenprocoumon (Marcumar ${ }^{\circledR}$; MEDA Pharma GmbH \& Co. KGaA, Bad Homburg, Germany) or warfarin (Coumadin ${ }^{\circledR}$; Bristol-Myers Squibb GmbH \& Co. $\mathrm{KGaA}$, Munich, Germany) prevent hepatic synthesis of coagulation factors II, VII, IX, and X by inhibiting vitamin $\mathrm{K}$-dependent $\gamma$-carboxylation. Due to the wide spectrum of food and drug interactions of VKAs, several pathological conditions, and the unpredictability of genetically determined interindividual differences in drug metabolism, treatment with VKA requires more or less frequent monitoring of the anticoagulant effect with dose adjustment. ${ }^{9}$ Regarding the problems and disadvantages of these drugs with respect to efficacy, safety, and quality of life, many efforts have been undertaken to develop new anticoagulants targeting only single factors of the coagulation cascade.

The licensed drugs rivaroxaban (Xarelto ${ }^{\circledR}$; Bayer Pharma AG, Leverkusen, Germany), dabigatran (Pradaxa ${ }^{\circledR}$; Boehringer Ingelheim $\mathrm{GmbH}$, Ingelheim, Germany), and apixaban (Eliquis $^{\circledR}$; Bristol-Myers Squibb GmbH \& Co. KGaA; Pfizer Pharma GmbH; Munich, Germany) are already available for clinical use in many countries for stroke prevention in AF. Other new substances targeting factor Xa such as edoxaban (Lixiana ${ }^{\circledR}$; Daiichi Sankyo Company, Limited, Tokyo, Japan) are in final stages of clinical studies. The predictability of these new oral direct anticoagulants is based on their pharmacodynamic and pharmacokinetic profiles. Unlike VKAs, multiple food and drug interactions are not seen with NOAC and, thus, routine monitoring with laboratory tests is not recommended.

\section{The pharmacokinetic profiles of NOAC}

Rivaroxaban as the first direct oral factor $\mathrm{Xa}$ inhibitor is a small molecule (molecular weight $436 \mathrm{~g} / \mathrm{mol}$ ) that is almost insoluble in water and exhibits high plasma protein binding (92\%-95\%) in humans, with serum albumin being the main binding component. The absolute bioavailability of rivaroxaban is high $(80 \%-100 \%)$ and is not affected by food intake. In patients with nonvalvular atrial fibrillation receiving Xarelto ${ }^{\circledR} 20 \mathrm{mg}$ once daily, median maximal concentration $\left(\mathrm{C}_{\max }\right)$ at steady state reaches approximately $290 \mu \mathrm{g} / \mathrm{L}$ (5th-95th percentile: $195-420 \mathrm{ng} / \mathrm{mL})$ and a trough concentration $\left(\mathrm{C}_{\text {trough }}\right)$ of approximately $32 \mu \mathrm{g} / \mathrm{L}(5 \mathrm{th}-95 \mathrm{th}$ percentile: 5-87 $\mathrm{ng} / \mathrm{mL}$ ). Rivaroxaban has a dual mode of excretion with the renal route accounting for one third of the overall elimination of unchanged active drug. ${ }^{10-12}$

Apixaban as second direct oral factor Xa inhibitor with good bioavailability and a half-life of approximately 12 hours has high affinity for factor Xa similar to rivaroxaban, and inhibits free factor $\mathrm{Xa}$, factor $\mathrm{Xa}$ in the prothrombinase complex, and factor Xa bound to platelets. Absorption of apixaban is approximately $50 \%$. Following oral administration, peak plasma concentrations are observed at about 3-4 hours post dosing. Apixaban is $87 \%$ bound to plasma proteins. Apixaban is eliminated predominantly via the fecal route (56\%), with $25 \%-29 \%$ of the recovered dose eliminated via urinary excretion. In patients receiving Eliquis ${ }^{\circledR} 5$ $\mathrm{mg}$ twice daily, mean $\mathrm{C}_{\text {trough }}$ and $\mathrm{C}_{\max }$ reaches approximately 19-162 ng/mL. ${ }^{12}$

Edoxaban is another oral reversible direct factor $\mathrm{Xa}$ inhibitor with $62 \%$ oral bioavailability. It achieves maximum concentrations within 1-2 hours, its mean terminal elimination half-life is $8.75-10.4$ hours. Edoxaban is primarily eliminated unchanged through multiple pathways, with approximately $50 \%$ of systemically absorbed drug eliminated via renal excretion. The most abundant metabolites are formed through hydrolysis with minor contribution from cytochrome P450-3A. ${ }^{13}$

Dabigatran etexilate is a potent synthetic nonpeptide competitive rapidly acting oral direct thrombin inhibitor. Dabigatran is taken orally as a prodrug in its inactive precursor form, dabigatran etexilate, which is converted after absorption by nonspecific esterases to the active substance 


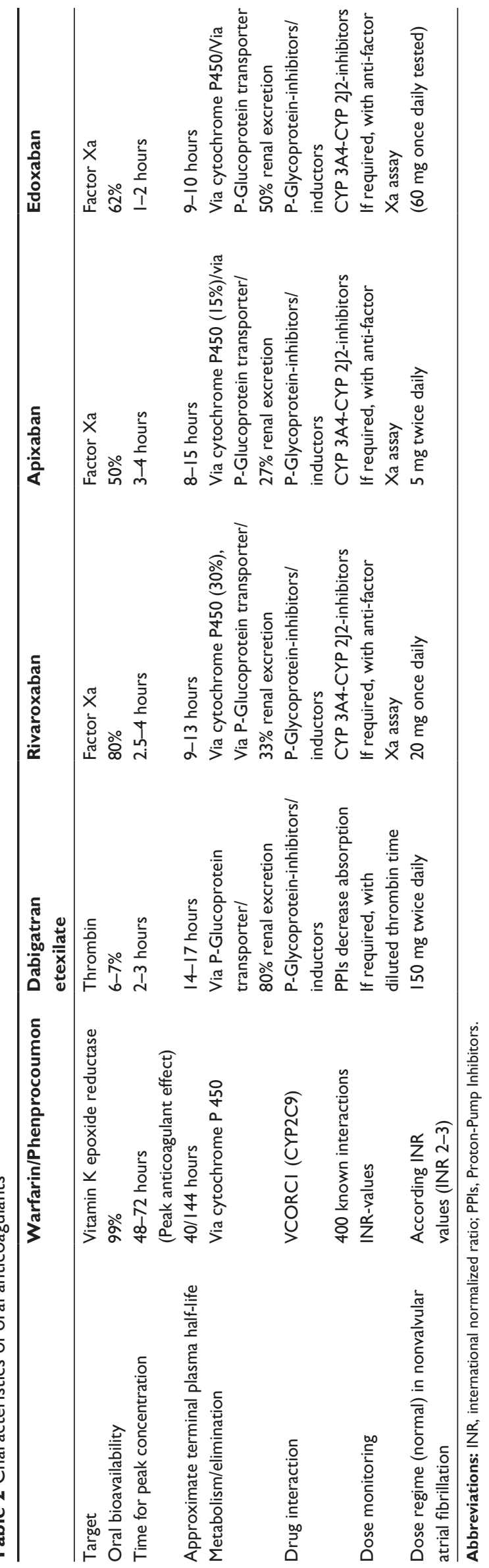

that inhibits thrombin directly. In the treatment of atrial fibrillation, for which dabigatran was approved by the Food and Drug Administration and the European Medicine Agency (in 2011), patients had a twice daily regimen of $150 \mathrm{mg}$. Pradax ${ }^{\circledR}$ is prescribed as having a $\mathrm{C}_{\text {max }}$ at steady state of $254 \pm 70.5 \mathrm{ng} / \mathrm{mL}$ (mean \pm standard deviation) and a $\mathrm{C}_{\text {trough }}$ after 12 hours of $80.3 \pm 18.7 \mathrm{ng} / \mathrm{mL}$ in elderly subjects. ${ }^{14,15}$

As seen in Table 2, the three NOAC, dabigatran, rivaroxaban, and apixaban, differ in mode of action (factor IIa and factor Xa inhibition), pharmacology, pharmacokinetic and pharmacodynamic parameters, drug interactions, and side effects.

\section{Efficacy and safety studies for prophylaxis of thromboembolism in nonvalvular atrial fibrillation of NOAC}

Dabigatran $\left(\operatorname{Pradaxa}^{\circledR}\right)$ was the first new oral anticoagulant to be approved based on the results of the Randomized Evaluation of Long-Term Anticoagulation Therapy (RE-LY) trial for the prevention of stroke and systemic embolism in patients with nonvalvular atrial fibrillation. ${ }^{16}$ In the RE-LY study, 18,113 patients with nonvalvular atrial fibrillation and at least one additional risk factor for stroke or systemic thromboembolism were randomized into two different treatment arms: dabigatran $150 \mathrm{mg}$ or $110 \mathrm{mg}$ twice daily or conventional therapy with the VKA warfarin in therapeutic international normalized ratio (INR)-targets of 2.0-3.0. Both dabigatran treatment regimes were statistically noninferior to the VKA in terms of the rate of primary efficacy endpoints (stroke and systemic embolism) as well as with respect to the primary safety endpoint (severe bleeding complications). The higher dabigatran dosing (150 mg twice daily) was significantly superior to the tested VKA in reducing the primary efficacy endpoints, without increasing the risk of bleeding. The lower dosing $(110 \mathrm{mg}$ twice daily) showed a comparable effectiveness in terms of preventing stroke and thromboembolism, while the risk of bleeding complications was significantly lower. Interestingly, both dabigatran dosage regimes were associated with a significantly lower risk of intracranial bleeding compared to the VKA. Clinically relevant side effects in gastrointestinal complaints (dyspepsia) and gastrointestinal bleeding occurred more frequently among dabigatran treated patients.

Rivaroxaban $\left(\right.$ Xarelto $^{\circledR}$ ) was the first oral factor Xa inhibitor to have gained approval for the prophylaxis of thromboembolism in nonvalvular atrial fibrillation. In the double-blind randomized pivotal trial Rivaroxaban Once-daily, oral, direct factor Xa inhibition Compared with vitamin $\mathrm{K}$ antagonism 
for prevention of stroke and Embolism Trial in Atrial Fibrillation (ROCKET-AF), a high risk population of approximately 14,000 patients with nonvalvular atrial fibrillation was included; patients had at least two risk factors or had history of stroke, transitory ischemic attack, or systemic embolism (average $\mathrm{CHADS}_{2}$ score: 3.5$) .{ }^{17}$ Rivaroxaban $20 \mathrm{mg}$ once daily was compared with the VKA warfarin at INR target of 2.0-3.0. Patients with impaired renal function (creatinine clearance of 30-49 $\mathrm{mL} /$ minute) were treated with a reduced rivaroxaban dose of $15 \mathrm{mg}$ once daily. In the statistical analyses, a noninferiority of rivaroxaban compared to the conventional treatment with warfarin could be demonstrated for preventing thromboembolic complications and safety. In the on-treatment analysis, rivaroxaban resulted in a significant reduction in the primary efficacy endpoint consisting of stroke and systemic embolism compared to with the VKA. The primary safety endpoint of the study consisted of all bleeding complications (severe and nonsevere clinically significant bleeding) and was not significantly different in both study treatment arms. Rivaroxaban was associated with a significantly lower risk for intracranial bleeding and fatal bleeding complications.

Apixaban (Eliquis ${ }^{\circledR}$ ) as second oral factor Xa inhibitor was examined in two randomized, multicenter studies in patients with atrial fibrillation. In the Apixaban versus Acetylsalicylic acid to prevent strokes (AVERROES) trial, 5,599 patients with atrial fibrillation and at least one additional risk factor were double-blind randomized. ${ }^{18}$ Patients who were not suitable for treatment with VKA and, were either treated with acetylsalicylic acid (ASA) at doses of 81-324 mg once daily or apixaban at a dosing of $5 \mathrm{mg}$ twice daily. It has long been known that ASA has only a limited antithrombotic effect in atrial fibrillation; therefore, apixaban could demonstrate its superior antithrombotic activity compared to ASA. The risk of suffering stroke or embolism was approximately halved under apixaban treatment. Remarkably, the bleeding rates among apixaban were not significantly increased in comparison to ASA. Due to the superior benefit-risk profile of apixaban, the study has been terminated prematurely. It was finally investigated in the Apixaban for Reduction in Stroke and Other Thromboembolic Events in Atrial Fibrillation (ARISTOTLE)-trial whether apixaban in the dosing of $5 \mathrm{mg}$ twice daily is non-inferior to warfarin at target-INR of $2-3 .{ }^{19}$ The study design was double-blind and randomized, and included patients with nonvalvular AF and one additional risk factor (average $\mathrm{CHADS}_{2}$ score: 2.1). Patients with increased risk of bleeding and the presence of two risk markers (age $>80$ years, body weight less than $60 \mathrm{~kg}$, creatinine $>1.5 \mathrm{mg} /$ $\mathrm{dL}$ ) were treated with the lower dose of apixaban $2.5 \mathrm{mg}$ twice daily. The primary endpoints consisted of stroke and systemic embolism. Both the risk of stroke and systemic embolism and the risk of major bleeding complications were statistically significantly lower with apixaban than with warfarin. Moreover, apixaban had an impact on the mortality of the patients that was significantly reduced in the statistical analyzes in comparison to warfarin.

Edoxaban $\left(\right.$ Lixiana $\left.^{\circledR}\right)$, another oral factor Xa inhibitor, was studied in a large multicenter phase III trial versus warfarin in subjects with AF: ENGAGE AF-TIMI 48. ${ }^{20}$ With more than 20,000 patients, this study was the largest and longest single comparative clinical trial performed for prevention of embolic events in nonvalvular AF. Two edoxaban regimens (30 or $60 \mathrm{mg}$ once daily) were tested for noninferiority in comparison to warfarin during the treatment period of 2.8 years. The primary efficacy endpoint was stroke or systemic embolism. Both oncedaily regimens of edoxaban were noninferior to warfarin with respect to the prevention of stroke or systemic embolism and were associated with significantly lower rates of bleeding and death from cardiovascular causes.

All studies, which compared the efficacy and safety of the new direct oral anticoagulants, used dose-adjusted warfarin as standard of control and showed noninferiority or superiority for the efficacy outcome of ischemic stroke and systemic embolism. Furthermore, the rates of major bleeding complications were similar or even reduced for the new drugs in comparison with warfarin. ${ }^{21}$ Table 3 summarizes the results for efficacy and safety data of dabigatran, rivaroxaban, apixaban, and edoxaban based on the RE-LY, ROCKET AF, ARISTOTLE, and ENGAGE AF-TIMI 48 trials.

No clinical comparisons regarding efficacy and safety outcomes between the new direct oral drugs have been performed with patient cohorts, and it is highly unlikely that such a comparison would be performed in the near future due to the expense and risks to the manufacturer of such an undertaking.

\section{Health outcomes and patients' quality of life}

The VKA such as warfarin, acenocoumarol, and phenprocoumon require drug monitoring mainly due to their narrow therapeutic window and numerous food and drug interactions. The relationship between monitoring VKAs and their efficacy/ safety balance is proven. ${ }^{22,23}$ The exponential increase in studies evaluating health-related quality of life as an important outcome in anticoagulated patients has shown that monitoring these patients leads to more anticoagulation stability, lower incidence of bleeding, and less ischemic events. ${ }^{24-30}$

However, active changes in lifestyle can be potentially troublesome for many patients. Qualitative studies have 
Table 3 Efficacy and safety studies of the direct oral anticoagulants dabigatran, rivaroxaban, apixaban, and edoxaban

\begin{tabular}{|c|c|c|c|c|}
\hline & Dabigatran etexilat RE-LY & Rivaroxaban ROCKET-AF & Apixaban ARISTOTLE & $\begin{array}{l}\text { Edoxaban ENGAGE } \\
\text { AF-TIMI } 48\end{array}$ \\
\hline $\begin{array}{l}\text { Number of } \\
\text { patients }\end{array}$ & 18,113 & 14,264 & $|8,20|$ & 21,105 \\
\hline $\begin{array}{l}\text { Patient } \\
\text { population }\end{array}$ & $\begin{array}{l}\text { Nonvalvular atrial fibrillation; } \\
\mathrm{CHADS}_{2} \text { score } \geq \text { I (mean: } 2 . \mathrm{I} \text { ) } \\
\text { Mean age: } 72 \text { years }\end{array}$ & $\begin{array}{l}\text { Nonvalvular atrial fibrillation; } \\
\mathrm{CHADS}_{2} \text { score } \geq 2 \text { (mean: } 3.5 \text { ) } \\
\text { Mean age: } 73 \text { years }\end{array}$ & $\begin{array}{l}\text { Nonvalvular atrial fibrillation; } \\
\mathrm{CHADS}_{2} \text { score } \geq \mathrm{I} \text { (mean: } 2 . \mathrm{I} \text { ) } \\
\text { Mean age: } 70 \text { years }\end{array}$ & $\begin{array}{l}\text { Nonvalvular atrial fibrillation; } \\
\mathrm{CHADS}_{2} \text { score } \geq 2 \text { (mean: } 2.8 \text { ) } \\
\text { Mean age: } 72 \text { years }\end{array}$ \\
\hline Study design & $\begin{array}{l}\text { Double-blind, randomized, } \\
\text { noninferiority trial }\end{array}$ & $\begin{array}{l}\text { Double-blind, randomized, } \\
\text { noninferiority trial }\end{array}$ & $\begin{array}{l}\text { Double-blind, randomized, } \\
\text { noninferiority trial }\end{array}$ & $\begin{array}{l}\text { Double-blind, randomized, } \\
\text { noninferiority trial }\end{array}$ \\
\hline Dosage & $150 \mathrm{mg}(\mathrm{I} 10 \mathrm{mg})$ twice daily & $20 \mathrm{mg}$ (I5 mg) once daily & $5 \mathrm{mg}(2.5 \mathrm{mg})$ twice daily & $60 \mathrm{mg}(30 \mathrm{mg})$ once daily \\
\hline Control drug & $\begin{array}{l}\text { Warfarin (INR 2-3) } \\
\text { TTR 64\% }\end{array}$ & $\begin{array}{l}\text { Warfarin (INR 2-3) } \\
\text { TTR 55\% }\end{array}$ & $\begin{array}{l}\text { Warfarin (INR 2-3) } \\
\text { TTR } 62 \%\end{array}$ & $\begin{array}{l}\text { Warfarin (INR 2-3) } \\
\text { TTR } 68.4\end{array}$ \\
\hline $\begin{array}{l}\text { Efficacy } \\
\text { endpoint }\end{array}$ & $\begin{array}{l}\text { Stroke or systemic } \\
\text { embolism }\end{array}$ & $\begin{array}{l}\text { Stroke or systemic } \\
\text { embolism }\end{array}$ & $\begin{array}{l}\text { Stroke or systemic } \\
\text { embolism }\end{array}$ & $\begin{array}{l}\text { Stroke or systemic } \\
\text { embolism }\end{array}$ \\
\hline Safety endpoint & Major bleeding & Major bleeding & Major bleeding & Major bleeding \\
\hline Results relative & Efficacy: $0.66(0.53-0.82)$ & Efficacy: 0.88 (0.75-I.03) & Efficacy: 0.80 (0.67-0.95) & Efficacy: 0.88 (0.75-I.02) \\
\hline risk $(95 \% \mathrm{Cl})$ & $\begin{array}{l}\text { Safety: } 0.93 \text { (0.8I-I.07) } \\
\text { I } 50 \text { mg bid: Efficacy: } \uparrow \\
\text { Safety: } \leftrightarrow \\
\text { I I } 0 \text { mg bid: Efficacy: } \leftrightarrow \\
\text { Safety: } \uparrow\end{array}$ & $\begin{array}{l}\text { Safety: I.03 (0.96-I.I I) } \\
\text { Efficacy: } \leftrightarrow \\
\text { Safety: } \leftrightarrow\end{array}$ & $\begin{array}{l}\text { Safety: } 0.69(0.60-0.80) \\
\text { Efficacy: } \uparrow \\
\text { Safety: } \uparrow\end{array}$ & $\begin{array}{l}\text { Safety: } 0.80(0.7 \mathrm{I}-0.90) \\
\text { Efficacy: } \leftrightarrow \\
\text { Safety: } \uparrow\end{array}$ \\
\hline
\end{tabular}

Notes: $\uparrow$ signifies "superior"; $\leftrightarrow$ signifies "non-inferior".

Abbreviations: bid, twice daily; Cl, confidence interval; INR, international normalized ratio; TTR, mean percent of time in the therapeutic range; RE-LY, Randomized Evaluation of Long-Term Anticoagulation Therapy trial; ARISTOTLE, Apixaban for Reduction in Stroke and Other Thromboembolic Events in Atrial Fibrillation trial; ROCKET-AF, Rivaroxaban Once-daily, oral, direct factor Xa inhibition Compared with vitamin $\mathrm{K}$ antagonism for prevention of stroke and Embolism Trial in Atrial Fibrillation.

confirmed that frequent monitoring of blood tests and visits to the clinic, anxiety related to adverse events, patient autonomy, dietary restrictions, and the impact of anticoagulant medication on physical activities have a negative impact on the health-related quality of life. ${ }^{24}$ Moreover, it is often intended that the oral anticoagulation should be maintained over the long term, sometimes for the remainder of patient's life.

Advantages of NOAC include the wide therapeutic window, low inter- and intraindividual variability of the dose-effect relation, and only few known drug interactions or genetic determinations of the metabolism; thus, their clinical use is easy to handle, and frequent monitoring and dose adjustments have not been considered necessary. However, there are several situations in which it may be of assistance to assess the anticoagulant effects, even of NOAC such as rivaroxaban, apixaban, or dabigatran. ${ }^{31,32}$

In patients with severe renal impairment (creatinine clearance $<30 \mathrm{~mL} /$ minute) plasma levels may be significantly increased, which may lead to an increased bleeding risk when treated with rivaroxaban or apixaban. The use of these two oral factor Xa inhibitors is not recommended in patients with creatinine clearance $<15 \mathrm{~mL} /$ minute and are used with caution in patients with creatinine clearance between 15 and 29 $\mathrm{mL} /$ minute, as suggested in the summary characteristics of the products. ${ }^{33,34}$ Clinical case reports suggested that lower exposure of rivaroxaban or apixaban in patients with high body weight
$(>120 \mathrm{~kg})$ did not result in loss of drug efficacy. ${ }^{35}$ Dose adjustment based on low body weight may also not be warranted; however, combination of additional risk factors for bleeding (age $\geq 80$ years, body weight $\leq 60 \mathrm{~kg}$, and serum creatinine $\geq 1.5 \mathrm{mg} / \mathrm{dL}$ ) might lead to dose adjustment. As substrates of CYP3A4 and P-glycoprotein, rivaroxaban and apixaban are not recommended for concomitant use with strong inhibitors of both pathways, eg, most azole antimycotics and protease inhibitors.

Since dabigatran is eliminated primarily by renal excretion, the use of low dosage is recommended at a reduced kidney function and also at an increased risk of bleeding in patients, as well as in the elderly ( $\geq 75$ years). ${ }^{36-39}$ A corresponding control value of the renal function before starting treatment and subsequently is required at regular intervals. In severe renal insufficiency (creatinine clearance $<30 \mathrm{~mL} /$ minute), there is a contraindication for dabigatran due to accumulation.

Currently, there is no specific antidote for the direct oral anticoagulants available. The anticoagulation with VKA can be reversed by vitamin $\mathrm{K}$ injections. Oral vitamin $\mathrm{K}$ will lower the INR within 24 hours. Intravenous vitamin K can lower the INR more quickly than oral vitamin K, but at 24 hours, intravenous and oral vitamin K produce similar degrees of INR correction. ${ }^{40}$ Due to the long half-life of VKA, the antidote vitamin $\mathrm{K}$ for bleeding takes at least 12 hours to affect INR. Therefore, for more serious bleedings with VKA, other additional treatments are recommended. 
Fresh frozen plasma, prothrombin-complex concentrate, and recombinant factor VIIa have been used as general hemostatic agents in patients treated with anticoagulants who experience severe hemorrhage. ${ }^{41,42}$ For the NOAC, the management of bleeding can also be performed with these hemostatic agents. However, the effectiveness of these nonspecific agents for reversing the effect anticoagulation has not been established; there are only case reports of potential reversal agents, which showed dose dependent reversal of the anticoagulant effect of the NOAC. Due to the short half-lives and dose omission of NOAC, the anticoagulant effect may be reduced rapidly within hours without taking further action. Therefore, less serious bleedings with NOAC might be more easily managed than bleedings with VKA. However, there has been intensive effort to develop more specific antidotes for the new oral anticoagulants. The modified recombinant protein (r-Antidote, PRT064445) is a specific antidote for reversal of anticoagulation by direct and indirect inhibitors of coagulation factor Xa, already prooved in animal models of bleeding. ${ }^{43}$ An antidote specific for dabigatran (aDabi-Fab) has been shown to effectively reverse the anticoagulant activity of dabigatran in vivo in a rat model of anticoagulation. ${ }^{44}$ Moreover, it is reported that a synthetic small molecule (PER977) reduces blood loss by reversing the anticoagulant activity of apixaban, rivaroxaban, and dabigatran in a rat tail transection assay. ${ }^{45}$

Over- or under-anticoagulation may lead to serious bleeding or increased risk of embolic and thrombotic events. ${ }^{46}$ Regarding VKA, the time expressed in percentages that patients spend in therapeutic INR range is less than half in routine practice than in clinical trial settings. ${ }^{47,48}$ For NOAC, no routine monitoring is mandatory. Therefore, the level of treatment satisfaction and efficacy will be unknown till an event appears.

Health-related parameters such as physical function, vitality, and general health can be easily measured. However, the major concern of doctors that oral anticoagulation, whether new or old, will lead to hemorrhage or thrombosis will mostly be solved by regular blood testing and contact with medical practitioners. ${ }^{22-30}$ As mentioned, in patients over 70 years of age, the risk of a bleeding events is twice as high as in patients younger than 70 years of age. Moreover, when considering the elderly, adherence, and quality of life, it must be remembered that not all NOAC (ie, dabigatran) are suitable for dosette boxes. Dabigatran must remain in its original packing up until it is taken to protect it from moisture. The oral bioavailability may be decreased if the drug remains open for days in the dosette boxes, and increased by $75 \%$ compared to the reference capsule formulation when the pellets are taken without the capsule shell. ${ }^{36}$ Incorrect handling may, therefore, lead to higher risk for bleeding or thrombotic events, especially in elderly patients. Therefore, regular blood testing and visits to the doctors reassures effective treatment and health outcome, especially in the elderly.

To improve the treatment with coumarin derivatives a standard method for reporting the prothrombin time has been assessed to ensure the proper dosage intensity that decreases the risk of bleeding while maintaining the therapeutic efficacy of the vitamin $\mathrm{K}$ antagonists. The target specific inhibitors dabigatran, rivaroxaban and apixaban represent a new class of anticoagulants that can not be monitored with global coagulation tests due there is not a predictable linear relationship between laboratory value and drug concentration. ${ }^{49-56}$ Chromogenic anti-factor Xa assays have been demonstrated to have the potential for accurate measurement of plasma concentrations of the direct factor Xa inhibitors. ${ }^{57-60}$ However, the threshold values of drug concentrations and the degree of prolongation that might still be assumed as safe must be defined. Moreover, an exact cutoff that defines a clearly increased hemorrhagic risk at trough levels of direct factor Xa inhibitors has to be defined; such threshold values are only available for dabigatran. The thrombin time (TT) is reported to be very sensitive to low concentrations of dabigatran. ${ }^{61,62} \mathrm{~A}$ normal TT indicates that dabigatran is either absent or at a negligible low concentration. In cases of acute emergency operations, when the detection of low dabigatran concentrations might be necessary, the TT assay provides qualitative information regarding the presence of dabigatran. A diluted TT assay can be used to accurately measure dabigatran concentrations. Due to the linear doseresponse curves over a wide concentration range, a diluted TT assay can be used to accurately monitor both trough and peak dabigatran levels.

However, if oral anticoagulation stability could be more easily achieved over time, patients would suffer less adverse events and need less frequent blood controls. Different models of anticoagulation treatment might have different impacts on patients' satisfaction. A basic need in improving the satisfaction of a patient is to first know what individual habits and social surroundings the patient has.

\section{Cost analyses}

For future practice, the physicians need to consider which patients with atrial fibrillation are best suited for treatment with the new direct oral anticoagulants, and whether it makes sense to switch patients with preexisting and 
- NOAC have a wide therapeutic window, low inter-and intraindividual variability

- NOAC can be used in fixed doses without laboratory-guided dose adjustment

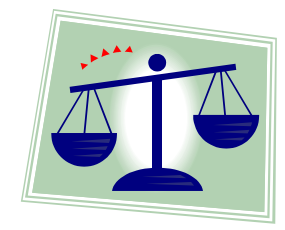

- Drug monitoring might be beneficial for patients with renal or hepatic impairment or in emergency situations $\Rightarrow$ assays only available in coagulation laboratories

- No specific antidote or method for reversing the antithrombotic effect is yet established

- Due to shorter half-lives, the status of adherence and compliance has to be checked

- Higher acquisition costs relative to VKA $\Rightarrow$ ability to pay for long-term treatment has to be ensured

Figure I Issues to be considered for treatment with NOAC

Abbreviations: NOAC, new oral anticoagulants; VKA, vitamin $\mathrm{K}$ antagonists.

well-adjusted VKA therapy to NOAC. The decision to switch patients to NOAC should also take economic considerations into account.

VKA represent the gold standard therapy for the prevention of thromboembolic complications in atrial fibrillation. ${ }^{63}$ Moreover, VKA have now reached the lowest mean cost for the defined daily dose; in Germany in 2013, the daily cost was $0.20 €$ for phenprocoumon, $3.28 €$ for dabigatran and rivaroxaban, and $3.43 €$ for apixaban. Even when event costs, INR-testing, physician visits, or prescription drug costs in a long-term 30-year model are invoiced, as performed by Harrington et al, ${ }^{64}$ warfarin had the lowest mean cost of $\$ 77,813$, followed by rivaroxaban $20 \mathrm{mg}(\$ 78,738)$, dabigatran $150 \mathrm{mg}(\$ 82,719)$, and apixaban $5 \mathrm{mg}(\$ 85,326)$ for a baseline patient (defined as a 70-year-old patient with $\mathrm{AF}$ with an increased risk for stroke CHADS $_{2}>1$ or equivalent], a renal creatinine clearance of $>50 \mathrm{~mL} /$ minutes, and no previous contraindications to anticoagulant therapy). For a baseline 65-year-old patient with $\mathrm{AF}$ and $\mathrm{CHADS}_{2}>1$ or equivalent in a time range over 20 years, the cost-utility analysis for warfarin ranged from 7,622€ to $9,069 €$ and for NOAC from $19,537 €$ to $20,048 € .{ }^{65}$

Self-management entails the measurement of the INR by the patient using point-of-care devices and, when necessary, self-adjustment of the VKA dosage. ${ }^{27-30}$ In the review of Regier et al, ${ }^{66}$ start-up cost in Canada for selfmanaging treated patients was estimated to be $\$ 1,567$ per patient, and the annual cost of physician management and self-management was estimated to be $\$ 357$ and $\$ 352$, respectively, per patient. Self-management for NOACtreated patients has not been considered because the novel drugs are established without drug monitoring, and no point-of-care device is now available for monitoring NOACtherapy. However, the total acute cost for a major thrombotic event is $\$ 14,428$. The cost of a major hemorrhage event is estimated to be $\$ 6,003$. After a major event, patients with mild disability underwent 1 year of rehabilitation at a cost of $\$ 2,176$. For those with permanent disability, an average yearly cost of $\$ 33,532$ for care was estimated.

However, data of efficacy from large randomized trials exists for NOAC, ${ }^{16-20}$ and they showed the reduction of major adverse bleeding events with NOAC. This is likely to lower the overall health care costs in comparison to following the VKA strategy, though it is hard to get a real-world cost estimate for this.

\section{Conclusion}

By now, three direct oral anticoagulants - dabigatran, rivaroxaban, and apixaban - are approved for stroke prevention in patients with nonvalvular AF.

Among the factors of oral anticoagulation that induce dissatisfaction, lifestyle limitations reduce quality of life the most. VKA as current standard therapy used for prolonged stroke management have a narrow therapeutic window, interindividual variability in dose response, and numerous drug-drug and drug-food interactions. The direct 
oral anticoagulants are effective alternatives to warfarin or phenprocoumon.

However, special care is indicated in patients with increased risk of bleeding or with renal or hepatic insufficiency. Dose reductions have to be considered in such cases. Moreover, older patients represent a particularly difficult cohort of patients in which both the thromboembolic risk and the risk of bleeding are increased. In these patient cohorts monitoring anticoagulation therapy may be helpful in optimizing therapy with the direct oral anticoagulants. Methods for accurate and effective monitoring of direct oral anticoagulants are available. In order to accurately estimate the cost, the cost differences of the various anticoagulant drugs have to be calculated, but also the costs of monitoring VKA versus measuring NOACconcentrations in special clinical situations, the cost of bleeding events, and the costs of stroke have to be considered. Uncertainties in clinical practice, that may be solved in the near future, arise in particular from: the lack of availability of specific antidotes for rapid antagonism of the anticoagulant effect of direct thrombin or factor Xa inhibitors; the lack of validated point-of-care tests to monitor and review the quality of anticoagulation in certain emergency situations (for example, in acute bleeding and chronic renal insufficiency); and from the absence of clinical data on the management of bleeding under direct oral anticoagulants or perioperative switching and bridging (timely discontinuation and resumption in operations). There are also no data on possible interactions with other drugs in the presence of much comorbidity. In figure 1 some issues that have to be considered for treatment with NOAC are mentioned. Therefore, it has to be carefully considered if using fixed doses without laboratory-guided dose adjustment is a real benefit for patients' quality of life and adherence. To conclude, individual patients' satisfaction profiles are influenced by many factors, and have to be adjusted with physicians' satisfaction profiles.

\section{Disclosure}

The authors report no conflicts of interest in this work.

\section{References}

1. Virchow, RLK. Thrombosis und Emboli (1846-1856) In: Klassiker der Medizin Edited by Karl Sudhoff Von Johann Ambrosius Barth V. 1910, Leipzig (Matzdorff AC, Bell WR transl). Canton, Science History Publications, 1998] pp 32, 49, 50,53, 56, 62, 110, 169.

2. Albers GW, Dalen JE, Laupacis A, Manning WJ, Petersen P, Singer DE. Antithrombotic therapy in atrial fibrillation. Chest. 2001;119(Suppl 1): 194S-206S.

3. Go AS, Hylek EM, Phillips KA, et al. Prevalence of diagnosed atrial fibrillation in adults: national implications for rhythm management and stroke prevention: the AnTicoagulation and Risk Factors in Atrial Fibrillation (ATRIA) Study. JAMA. 2001;285:2370-2375.
4. Naccarelli GV, Panaccio MP, Cummins G, Tu N. CHADS2 and CHA2DS2-VASc risk factors to predict first cardiovascular hospitalization among atrial fibrillation/atrial flutter patients. Am J Cardiol. 2012;109(10):1526-1533.

5. Friberg L, Rosenqvist M, Lip GY. Evaluation of risk stratification schemes for ischaemic stroke and bleeding in 182678 patients with atrial fibrillation: the Swedish Atrial Fibrillation cohort study. Eur Heart J. 2012;33(12):1500-1510.

6. European Heart Rhythm Association; European Association for Cardio-Thoracic Surgery, Camm AJ, et al. Guidelines for the management of atrial fibrillation: the Task Force for the Management of Atrial Fibrillation of the European Society of Cardiology (ESC). Eur Heart J. 2010;31:2369-2429.

7. Ansell J, Hirsh J, Poller L, Bussey H, Jacobson A, Hylek E. The pharmacology and management of the vitamin K antagonists: the Seventh ACCP Conference on Antithrombotic and Thrombolytic Therapy. Chest. 2004;126(Suppl 3):204S-233S.

8. You JJ, Singer DE, Howard PA, et al. Antithrombotic therapy for atrial fibrillation: Antithrombotic Therapy and Prevention of Thrombosis, 9th ed: American College of Chest Physicians EvidenceBased Clinical Practice Guidelines. Chest. 2012;141(Suppl 2): e531S-e575S

9. Hirsh J, Dalen J, Anderson DR, et al. Oral anticoagulants: mechanism of action, clinical effectiveness, and optimal therapeutic range. Chest. 2001;119(Suppl 1):8S-21S.

10. Mueck W, Lensing AW, Agnelli G, Decousus H, Prandoni P, Misselwitz F. Rivaroxaban: population pharmacokinetic analyses in patients treated for acute deep-vein thrombosis and exposure simulations in patients with atrial fibrillation treated for stroke prevention. Clin Pharmacokinet. 2011;50(10):675-686.

11. Perzborn E, Roehrig S, Straub A, Kubitza D, Mueck W, Laux V. Rivaroxaban: a new oral factor Xa inhibitor. Arterioscler Thromb Vasc Biol. 2010;30(3):376-381.

12. Mueck W, Schwers S, Stampfuss J. Rivaroxaban and other novel oral anticoagulants: pharmacokinetics in healthy subjects, specific patient populations and relevance of coagulation monitoring. Thromb $J$. 2013;11(1):10.

13. Ogata K, Mendell-Harary J, Tachibana M, et al. Clinical safety, tolerability, pharmacokinetics, and pharmacodynamics of the novel factor Xa inhibitor edoxaban in healthy volunteers. J Clin Pharmacol. 2010;50(7):743-753.

14. Stangier J, Clemens A. Pharmacology, pharmacokinetics, and pharmacodynamics of dabigatran etexilate, an oral direct thrombin inhibitor. Clin Appl Thromb Hemost. 2009;15 Suppl 1:9S-16S.

15. Clemens A, Haertter S, Friedman J, et al. Twice daily dosing of dabigatran for stroke prevention in atrial fibrillation: a pharmacokinetic justification. Curr Med Res Opin. 2012;28(2):195-201.

16. Healey JS, Eikelboom J, Douketis J, et al. Periprocedural bleeding and thromboembolic events with dabigatran compared with warfarin: results from the Randomized Evaluation of Long-Term Anticoagulation Therapy (RE-LY) randomized trial. Circulation. 2012;126(3):343-348.

17. Patel MR, Mahaffey KW, Garg J, et al. Rivaroxaban versus warfarin in nonvalvular atrial fibrillation. $N$ Engl J Med. 2011;365(10): 883-891.

18. Flaker GC, Eikelboom JW, Shestakovska O, et al. Bleeding during treatment with aspirin versus apixaban in patients with atrial fibrillation unsuitable for warfarin: the apixaban versus acetylsalicylic acid to prevent stroke in atrial fibrillation patients who have failed or are unsuitable for vitamin K antagonist treatment (AVERROES) trial. Stroke. 2012;43(12):3291-3297.

19. Wallentin L, Lopes RD, Hanna M, et al. Efficacy and safety of apixaban compared with warfarin at different levels of predicted international normalized ratio control for stroke prevention in atrial fibrillation. Circulation. 2013;127(22):2166-2176.

20. Giugliano RP, Ruff CT, Braunwald E, et al. Edoxaban versus warfarin in patients with atrial fibrillation. $N$ Engl J Med. 2013;369(22): 2093-2104. 
21. Kalus JS. Antithrombotic alternatives for stroke prevention in atrial fibrillation: critical differences and remaining questions. Drugs Context. 2013;2013:212251.

22. Bloomfield HE, Taylor BC, Krause A et al. Safe and Effective Anticoagulation in the Outpatient Setting: A Systematic Review of the Evidence. Washington (DC): Department of Veterans Affairs (US); 2011 VA Evidence-based Synthesis Program Reports.

23. Samsa GP, Matchar DB. Relationship between test frequency and outcomes of anticoagulation: a literature review and commentary with implications for the design of randomized trials of patient selfmanagement. J Thromb Thrombolysis. 2000;9:283-292.

24. Silva de Assis MC, Nascimento Cruz L, Zuchinali P, Rohde LE, Rejane Rabelo E. Does treatment guided by vitamin $\mathrm{K}$ in the diet alter the quality of life of anticoagulated patients? Nutr Hosp. 2012;27(4):1328-1333.

25. Matchar DB, Samsa GP, Cohen SJ, Oddone EZ, Jurgelski AE. Improving the quality of anticoagulation of patients with atrial fibrillation in managed care organizations: results of the managing anticoagulation services trial. Am J Med. 2002;113(1):42-51.

26. Cromheecke ME, Levi M, Colly LP, et al. Oral anticoagulation selfmanagement and management by a specialist anticoagulation clinic: a randomized cross-over comparison. Lancet. 2000;356(8):97-102.

27. Gadisseur AP, Breukink-Engbers WG, van der Meer FJ, van den Besselaar AM, Sturk A, Rosendaal FR. Comparison of the quality of oral anticoagulant therapy through patient self management and management by specialized anticoagulation clinics in the Netherlands. Arch Intern Med. 2003;163:2639-2646.

28. Casais P, Meschengieser SS, Sanchez-Luceros A, Lazzari MA. Patients' perceptions regarding oral anticoagulation therapy and its effect on quality of life. Curr Med Res Opin. 2005;21(7):1085-1090.

29. Gadisseur AP, Kaptein AA, Breukink-Engbers WG, van der Meer FJ, Rosendaal FR. Patient self-management of oral anticoagulant care vs management by specialized anticoagulation clinics: positive effects on quality of life. J Thromb Haemost. 2004;2(4):584-591.

30. Davis NJ, Billett HH, Cohen HW, Arnsten JH. Impact of adherence, knowledge, and quality of life on anticoagulation control. Ann Pharmacother. 2005;39(4):632-636.

31. Mani H, Kasper A, Lindhoff-Last E. Measuring the anticoagulant effects of target specific oral anticoagulants-reasons, methods and current limitations. J Thromb Thrombolysis. 2013;36(2):187-194.

32. Mismetti P, Laporte S. New oral antithrombotics: a need for laboratory monitoring. For. J Thromb Haemost. 2010;8(4):621-626.

33. European Medicines Agency. Xarelto-Summary of Product Characteristics. London: European Medicines Agency; 2013. Available from: http://www.ema.europa.eu/docs/en_GB/document_library/ EPAR_-_Summary_for_the_public/human/000944/WC500057109. pdf. Accessed April 24, 2014.

34. European Medicines Agency. Eliquis-Summary of Product Characteristics. London: European Medicines Agency; 2013. Available from: http://www.ema.europa.eu/docs/en_GB/document_library/ EPAR_-_Summary_for_the_public/human/002148/WC500107773. pdf. Accessed April 24, 2014.

35. Upreti VV, Wang J, Barrett YC, et al. Effect of extremes of body weight on the pharmacokinetics, pharmacodynamics, safety and tolerability of apixaban in healthy subjects. Br J Clin Pharmacol. 2013;76(6): 908-916.

36. European Medicines Agency. Pradaxa-Summary of Product Characteristics. London: European Medicines Agency; 2013. Available from: http://www.ema.europa.eu/docs/en_GB/document_library/ EPAR_-_Summary_for_the_public/human/000829/WC500041060. pdf. Accessed April 24, 2014.

37. Reilly PA, Lehr T, Haertter S, et al. RE-LY Investigators. The effect of dabigatran plasma concentrations and patient characteristics on the frequency of ischemic stroke and major bleeding in atrial fibrillation patients: the RE-LY Trial (Randomized Evaluation of Long-Term Anticoagulation Therapy).J Am Coll Cardiol. 2014;63(4):321-328.

38. Harper P, Young L, Merriman E. Bleeding risk with dabigatran in the frail elderly. N Engl J Med. 2012;366(9):864-866.
39. Legrand M, Mateo J, Aribaud A, et al. The use of dabigatran in elderly patients. Arch Intern Med. 2011;171(14):1285-1286.

40. Garcia DA, Crowther MA. Reversal of warfarin: case-based practice recommendations. Circulation. 2012;125(23):2944-2947.

41. Bershad EM, Suarez JI. Prothrombin complex concentrates for oral anticoagulant therapy-related intracranial hemorrhage: a review of the literature. Neurocrit Care. 2010;12(3):403-413.

42. Lauritzen B, Hedner U, Johansen PB, Tranholm M, Ezban M. Recombinant human factor VIIa and a factor VIIa-analogue reduces heparin and low molecular weight heparin (LMWH)-induced bleeding in rats. J Thromb Haemost. 2008;6(5):804-811.

43. Lu G, DeGuzman FR, Hollenbach SJ, et al. A specific antidote for reversal of anticoagulation by direct and indirect inhibitors of coagulation factor Xa. Nat Med. 2013;19(4):446-451.

44. Schiele F, van Ryn J, Canada K, et al. A specific antidote for dabigatran: functional and structural characterization. Blood. 2013;121(18): 3554-3562.

45. Laulicht B, Bakhru S, Lee C, et al. Small Molecule Antidote for Anticoagulants. Los Angeles: AHA; 2012. Available from: http://www. perosphere.com/content/presentations/documents/Perosphere_ISTH_ Talk.pdf. Accessed April 24, 2014.

46. Ogilvie IM, Newton N, Welner SA, Cowell W, Lip GY. Underuse of oral anticoagulants in atrial fibrillation: a systematic review. Am J Med. 2010;123(7):638-645. e4.

47. Connolly SJ, Pogue J, Eikelboom J, et al. Benefit of oral anticoagulant over antiplatelet therapy in atrial fibrillation depends on the quality of international normalized ratio control achieved by centers and countries as measured by time in therapeutic range. Circulation. 2008;118(20): 2029-2037.

48. Ageno W, Gallus AS, Wittkowsky A, et al. Oral anticoagulant therapy: Antithrombotic Therapy and Prevention of Thrombosis, 9th ed: American College of Chest Physicians Evidence-Based Clinical Practice Guidelines. Chest. 2012;141(Suppl 2): e44S-e88S.

49. Wienen W, Stassen JM, Priepke H, Ries UJ, Hauel N. In-vitro profile and ex-vivo anticoagulant activity of the direct thrombin inhibitor dabigatran and its orally active prodrug, dabigatran etexilate. Thromb Haemost. 2007;98:155-162.

50. Samama MM, Martinoli JL, LeFlem L, et al. Assessment of laboratory assays to measure rivaroxaban-an oral, direct factor $\mathrm{Xa}$ inhibitor. Thromb Haemost. 2010;103(4):815-825.

51. van Ryn J, Stangier J, Haertter S, et al. Dabigatran etexilate-a novel, reversible, oral direct thrombin inhibitor: interpretation of coagulation assays and reversal of anticoagulant activity. Thromb Haemost. 2010;103(6):1116-1127.

52. Tripodi A, Chantarangkul V, Guinet C, Samama MM. The International Normalized Ratio calibrated for rivaroxaban has the potential to normalize prothrombin time results for rivaroxaban-treated patients: results of an in vitro study. J Thromb Haemost. 2011;9(1):226-228.

53. Samama MM, Guinet C. Laboratory assessment of new anticoagulants. Clin Chem Lab Med. 2011;49(5):761-772.

54. Mani H, Hesse C, Stratmann G, Lindhoff-Last E. Rivaroxaban differentially influences ex vivo global coagulation assays based on the administration time. Thromb Haemost. 106(1):156-164.

55. Samama MM, Contant G, Spiro TE, et al. Evaluation of the prothrombin time for measuring rivaroxaban plasma concentrations using calibrators and controls: results of a multicenter field trial. Clin Appl Thromb Hemost. 2012;18(2):150-158.

56. Douxfils J, Mullier F, Robert S, Chatelain C, Chatelain B, Dogné JM. Impact of dabigatran on a large panel of routine or specific coagulation assays. Laboratory recommendations for monitoring of dabigatran etexilate. Thromb Haemost. 2012;107(5):985-997.

57. Asmis LM, Alberio L, Angelillo-Scherrer A, et al. Rivaroxaban: Quantification by anti-FXa assay and influence on coagulation tests: a study in 9 Swiss laboratories. Thromb Res. 2012;129(4):492-498.

58. Mani H, Rohde G, Stratmann G, et al. Accurate determination of rivaroxaban levels requires different calibrator sets but not addition of antithrombin. Thromb Haemost. 2012;108(1):191-198. 
59. Harenberg J, Krämer R, Giese C, Marx S, Weiss C, Wehling M. Determination of rivaroxaban by different factor Xa specific chromogenic substrate assays: reduction of interassay variability. J Thromb Thrombolysis. 2011;32(3):267-271.

60. Samama MM, Contant G, Spiro TE, et al. Evaluation of the anti-factor $\mathrm{X}$ a chromogenic assay for the measurement of rivaroxaban plasma concentrations using calibrators and controls. Thromb Haemost. 2012;107(2):379-387.

61. Stangier J, Feuring M. Using the HEMOCLOT direct thrombin inhibitor assay to determine plasma concentrations of dabigatran. Blood Coagul Fibrinolysis. 2012;23(2):138-143.

62. Curvers J, van de Kerkhof D, Stroobants AK, van den Dool EJ, Scharnhorst V. Measuring direct thrombin inhibitors with routine and dedicated coagulation assays: which assay is helpful? Am J Clin Pathol. 2012;138(4):551-558.

63. Hickey K. Anticoagulation management in clinical practice: preventing stroke in patients with atrial fibrillation. Heart Lung. 2012;41(2): $146-156$.
64. Harrington AR, Armstrong EP, Nolan PE, Malone DC. Costeffectiveness of apixaban, dabigatran, rivaroxaban, and warfarin for stroke prevention in atrial fibrillation. Stroke. 2013;44: $1676-1681$.

65. Krejczy M, Harenberg J, Marx S, Obermann K, Frölich L, Wehling M. Comparison of cost-effectiveness of anticoagulation with dabigatran, rivaroxaban and apixaban in patients with non-valvular atrial fibrillation across countries. J Thromb Thrombolysis. Epub September 25, 2013.

66. Regier DA, Sunderji R, Lynd LD, Gin K, Marra CA. Cost-effectiveness of self-managed versus physician-managed oral anticoagulation therapy. CMAJ. 2006;174(13):1847-1852.

\section{Publish your work in this journal}

Drug Design, Development and Therapy is an international, peerreviewed open-access journal that spans the spectrum of drug design and development through to clinical applications. Clinical outcomes, patient safety, and programs for the development and effective, safe, and sustained use of medicines are a feature of the journal, which has also been accepted for indexing on PubMed Central. The manuscript management system is completely online and includes a very quick and fair peer-review system, which is all easy to use. Visit http://www.dovepress.com/testimonials.php to read real quotes from published authors.

Submit your manuscript here: http://www.dovepress.com/drug-design-development-and-therapy-journal 